\title{
Effect of an Educational Program on Improving Quality of Nursing Care of Patients with Thalassemia Major as Regards Blood Transfusion
}

\author{
Azza Abd Alsemia Elewa ${ }^{1, *}$, Badria Abd Elshahed Ahmed Elkattan² \\ ${ }^{1}$ Lecturer of Pediatric Nursing Department, Faculty of Nursing, Helwan University, Cairo, Egypt \\ ${ }^{2}$ Lecturer of Adult Health Nursing Department, Faculty of Nursing, Helwan University, Cairo, Egypt \\ *Corresponding author: dr.azzaelewa@yahoo.com
}

\begin{abstract}
Quality of care is indicating that the right things are being done right, and is vital in improving the patient outcomes and safety. The aim of this study was to evaluate the effect of an educational program on improving quality of nursing care for patients with thalassemia major as regards blood transfusion. Research design: A quasi-experimental research design was utilized in this study. Research setting: The study was conducted at both in-and out-patient pediatric and adult medicine hematology departments affiliated to Ain Shams University Hospital. Sample: A purposive sample consisted of two groups: The first group included all nurses $(n=30)$ working in the above mentioned settings; and the second group included adolescent and adult patients with thalassemia major $(n=50)$, who were attending the above mentioned settings over a period of six months, they were chosen randomly. Tools: Data were collected through: (I) An interviewing questionnaire which include: sociodemographic data sheet for nurses and patients, nurse's knowledge sheet and routine blood transfusion knowledge questionnaire (RBTKQ) (II) An observational checklist to assess nurse's practice related to blood transfusion, assessment of the body system, measuring of vital signs and administration of intravenous iron chelation therapy. (III) Patient satisfaction scale. Based upon the actual need assessment of the study subjects an intervention program was designed and implemented. Results: The most important findings of the study revealed that, most of nurses had poor knowledge about blood transfusion and thalassemia. Besides, they don't follow a standard of quality of nursing care related to blood transfusion and other basic procedures as measuring of vital signs and administration of intravenous iron chelation therapy. In addition, the majority of patients were unsatisfied for quality of nursing care pre program, which improved to more than two thirds of patients were satisfied regarding quality of nursing care post program. The implementation of the education program has improved nurses' knowledge, practice and patients' satisfaction with statistically significant differences $(\mathrm{p}=<0.05,0.01 \& 0.01)$. Conclusion: Findings revealed that, the educational program had a positive effect on nurses' knowledge and practice related to thalassemia and blood transfusion, which improved quality of nursing care as well as increased patients' satisfaction. The study recommended that, a specialized orientation program should be developed for newly appointed nurses to prepare them before working at the hematology departments further studies should be conducted to improve nurses' knowledge and practice regarding to blood transfusion care of patients with thalassemia.
\end{abstract}

Keywords: educational program, quality of nursing care, thalassemia major, blood transfusion

Cite This Article: Azza Abd Alsemia Elewa, and Badria Abd Elshahed Ahmed Elkattan, "Effect of an Educational Program on Improving Quality of Nursing Care of Patients with Thalassemia Major as Regards Blood Transfusion.” American Journal of Nursing Research, vol. 5, no. 1 (2017): 13-21. doi: 10.12691/ajnr-5-1-2.

\section{Introduction}

Thalassemia is the most common inherited disorder in the world that represents a major public concern. It is characterized by a defect in the genes responsible for production of hemoglobin. Hemoglobin is a protein that consists of alpha and beta chains. If the genetic mutations prevent any formation of beta chains then beta-thalassemia occurs which involves abnormal development of red blood cells and eventually anemia $[1,2]$.
Children born with thalassemia major are normal at birth, but develop severe anemia during the first year of life. Other symptoms can include: Bone deformities in the face, fatigue, growth failure, shortness of breath and yellow skin (jaundice). Severe thalassemia can cause early death (between ages $20 \& 30$ years) due to heart failure [3]. Patients with beta thalassemia major need a life long treatment of regular blood transfusion every 3-4 weeks, and iron chelation therapy to remove iron from the body helps improve the outcome. So, thalassemia challenge for patients, their families and health care system since it requires a life-long treatment of blood transfusion and chelating drugs $[4,5]$. 
Blood transfusion is the mainstay of the care for individual with thalassemia major and many with intermediate. The purpose of transfusion is twofold: to improve the anemia and to suppress the ineffective erythropoiesis. Chronic transfusions prevent most of the serious growth, skeletal and neurological complications of thalassemia major [6]. In spite of its vital role in saving lives and enhancing patients' lives, blood transfusion is associated with risks. Making mistakes in blood transfusion and insufficient control of patients who receive blood during the transfusion can lead to death for such patients [7]. So, standards of safe blood transfusion must be developed and maintained to ensure a safe and rational approach to the use of blood transfusions in the management of these disorders, also careful consideration must be given to the associated dangers [6]. Nurses being responsible for the final bedside check before transfusion, have the final opportunity to prevent a mistransfusion. An understanding and knowledge of the pathophysiology of transfusion reactions, symptoms and treatment is essential to safely administer and monitor transfusions [8].

Quality of care is indicating that the right things are being done right, improving the outcomes for patients, their families and their communities. The criteria used to assess quality could address structure, process or outcome [9]. It is an optimal balance between possibilities realized and a framework of norms and values. Optimal nurse staffing is a critical component in improving the quality of patient care and preventing complications. The quality of nursing care makes a vital difference in patient outcomes and safety $[8,10]$.

Patient's satisfaction has been advocated as an outcome measure of quality nursing care. Determinants ofquality of nursing care include: adequate skill, caring attitudes, effective communication, efficient organizational and management systems and effective participation. Nurses need to understand that care cannot be of high quality unless the patient is satisfied. So, patient's satisfaction should thus remain a requirement for obtaining health care goals [11]. The nurse should be aware of his/her responsibility for the quality of care provision to the patients, the institution, ethics, laws and professional standards, as well as performance that contributes to the evaluation of care and the patients' satisfaction [12].

The nurse plays a critical role in any team of healthcare professionals involved in the care of patients with chronic diseases including hemoglobin ( $\mathrm{Hb}$ ) disorders such as thalassemia and sickle cell disease. These are extremely challenging diseases that are fatal if left untreated. However, by sharing expert knowledge on their prevention and treatment, these conditions can be effectively managed [13].

Nurse's education consists of the theoretical and practical training provided to nurses with the purpose to prepare them for their duties as nursing care professionals. It is very important for nursing staff to engage in plenty of ongoing training as well the needs of patients continue to change and there are new developments in procedure, the education of nurses never stops as they are required to continually master new skills and concepts throughout their career [14].

\subsection{Aim of the Study}

The aim of this study is to evaluate the effect of an educational program on improving quality of nursing care of patients with thalassemia major as regards blood transfusion.

\section{Through the following:}

1. Assessing nurses' knowledge and practices regarding thalassemia major and blood transfusion.

2. Planning, designing and implementing an education program regarding thalassemia major and blood transfusion.

3. Evaluating the effect of the education program regarding thalassemia major and blood transfusion on improving quality of nursing care.

\subsection{Research Hypothesis}

The educational program will improve the level of knowledge and practices of nurses regarding blood transfusion and quality of nursing care provided to patient.

The educational program will improve patient satisfaction regarding quality of nursing care provided to him/her.

\section{Subject and Methods}

\subsection{Design}

A quasi-experimental design has been utilized in this study.

\subsection{Setting}

The study was conducted at both in- and out- patient pediatric and adult medicine hematology departments affiliated to Ain Shams University Hospital.

\subsection{Sample}

A purposive sample consisted of two groups: The first group included all nurses $(n=30)$, working in the above mentioned settings, under the following inclusion criteria: Nurses who are willing to participate in the study, their ranges from $20->40$ years, nurses having experience from one to 20 years, both male and female nurses. Exclusion criteria: Nurses who are having more than 25 years of experience. The second group included of adolescent and adult patients with thalassemia major $(n=50)$, who were attending the above mentioned settings over a period of six months. They were chosen randomly under the following inclusion criteria: Patient's age ranges between 12 - 40 from both gender males and females and exclusion of patients suffering from other chronic medical diseases such as; positive hepatitis, renal failure, rheumatic heart disease, bronchial asthma, etc.)

\subsection{Tools and techniques Used for Data Collection}

\section{Tool 1: A structured designed interviewing questionnaire:}

Designed by the researchers after reviewing previous andrecent available related literature, it was written in simple Arabic language and it includes the following

a. Sociodemographic characteristics for nurses and patients including age, gender, marital status, qualifications and training about thalassemia etc. 
b. Nurse's knowledge about thalassemia, including meaning of thalassemia, causes, manifestations, types, complications, treatment and the effect of treatment on body system.

c. Routine Blood Transfusion Knowledge Questionnaire (RBTKQ) it was used to assess nurse's knowledge on blood transfusion developed byHijji, et al. [15] It consisted of 32 items that measure nurse's knowledge about blood transfusion (2 true-false; 20 multiple choice; \& 10 open questions). This section examines nurse's knowledge aspects of blood bag collection from blood bank and patient preparation prior to transfusion, pre/post transfusion initiation nursing responsibilities, and complications related to blood transfusion.

\section{Scoring system}

For nurse's knowledge about thalassemia and blood transfusion, nurse's knowledge was considered «poor» if the percentage was $<60 \%$, while it was considered «average» if the percentage was $60-<75 \%$, and was considered «good» if the percentage was $\geq 75 \%$.

Tool II: Comprises the following:

a- Blood transfusion observational checklist to assess nurses practices related to blood transfusion [16].

b- Assessment for nursing practices related to assessment of the body system, as measuring of vital signs (measurement of axillary's temperature, pulse and blood pressure) and administration of I.V iron chelation therapy [17].

\section{Scoring system}

Each item in the previous procedures was classified into two levels; «done "and «not done», if the nurses performed the steps correctly, one point was given, if incorrectly done or not done it at all, zero point was given. According to the actual practice for each study subject, it was categorized into unsatisfied $(<80 \%)$, and satisfied (80\% and more).

N.B: The observation checklist was filled in by the investigators.

\section{Tool III: Patient Satisfaction Scale (PSS):}

Developed by Risser [18], it was designed to evaluate patients' attitudes towards nurses and nursing care and originally contained three subscales with a total number of 25 items defined as follows:

1. Technical Professional (TP) domain contains seven items concerning technical issues on care and measurement of the nurse's behaviors, the main component of it is; the nurse gives good advice etc.

2. Educational Relationship (ER) domain contains seven items concerning nurse's attitude with patients, the exchange of information between the nurse and patient. The main components of it are; the nurse gives directions at the right speed, the nurse always gives complete enough explanations of why tests are ordered etc.

3. Trusting Relationship (TR) domain approaches contain eleven items concerning interpersonal relationship situations between nurse and patient, the verbal and nonverbal communication that occur between the nurse and patient. The main components of it are; the nurse should be more friendly than she is, the nurse is a person who can understand how I feel, the nurse is pleasant to be around etc.

\section{Scoring system}

Each question is assessed on a five - point Likert type measurement scale ranging from strongly agree (1), to
Strongly disagree (5).Both positive and negative sentences were included in each subscale. The negative sentences are assessed in reverse and the higher the score indicates the patient satisfaction with the nursing care provided.

\section{Operational Design}

\subsection{Preparatory Phase}

This phase included reviewing the available literature related to disease of thalassemia and blood transfusion to cover various aspects of the research problem using books, articles, magazines and internet search to develop the study tools for data collection.

\subsection{Reliability of the Tools}

Reliability was applied by the researcher for testing the internal consistency of the tool, by administration of the same tools to the same subjects under similar conditions on one or more occasions. Answers from repeated testing were compared $($ Test-re-test reliability $=0.7$ ).

\subsection{Validity of the Tools}

The study tools were tested for validity and reliability by a panel of 5 experts from the Faculty of Medicine (Pediatric \& Adult Medicine) and the Faculty of Nursing (Pediatric and Adult nursing).

\subsection{Pilot Study}

A pilot study was carried out on $10 \%$ (3 nurses \& 5 patients) of the study sample to test tools for clarity and applicability, and to determine the time required for filling in the tools. Data obtained from the pilot study were analyzed and accordingly the necessary modifications on the study tools were done: patients who participated in the pilot study were excluded from the main study sample to avoid bias.

\subsection{Field Work}

The actual fieldwork was carried out from the beginning of May 2015 until the end of November 2015, in the previously mentioned settings, where the researcher was available in the study settings twice/week from 9.00 a.m. to 12.00 p.m. The researchers were introduced themselves to the participant and explained the purpose of the study and its expected outcome, the participant is informed oral consent was obtained.

\section{Nursing Intervention:}

The program for nursing intervention was constructed in four phases:

Assessment phase: In this phase the researchers collected the following data:

- Demographic data of the patients and nurses.

- Nurse's knowledge about thalassemia.

- Nurse's knowledge about blood transfusion.

- Nurse's performance regarding blood transfusion, assessment of the body system, measuring vital signs and administration of I.V iron chelation therapy. 
- Patient's satisfaction regarding quality of nursing care.

\section{Planning phase}

The education program was designed by the researchers, based on the results obtained from the assessment phase. It was designed to improve nurse's knowledge and practice regarding thalassemia and blood transfusion and to improve patient's satisfaction. The intervention consisted of details about meaning of the disease, causes, manifestations, types and complications on body system; beside, knowledge and practice regarding blood transfusion.

\section{Implementation phase}

The education program was implemented over 7 months. The study group attended 6 sessions; 2 sessions for theory and 4 sessions for practice. The duration of each session ranged between 30-45 minutes. At the beginning of each session, the researchers started by giving a summary about the previous session and explaining the objective of the new one. Different teaching strategies were used including instructions, lectures, brainstorming, group discussion, clinical teaching and demonstration. The teaching aids used were handouts, colored posters and laptop screen show.

\section{Evaluation phase}

The effectiveness of the implemented program was assessed immediately through post test using the same pretest tools.

\section{Administrative Design}

The present study was carried out after taking an official permission from the administrators of the study settings at Ain Shams University Hospital, by submission of an official letter issued from the Faculty of Nursing, Helwan University, where the aim and expected outcomes of the study were explained clearly.

\subsection{Ethical Considerations}

An explanation of the aim of the study was given to nurses and patients before their enrollment in the study. An informed oral consent was obtained. Each study subject was individually interviewed using the previously mentioned study tools. They were assured that all the collected data will be used for research purpose only. Participants' anonymity, confidentiality, privacy, safety and protection were secured.

\section{Statistical Design}

Data were collected, revised, coded, analyzed, and tabulated using number and percentage distribution. Variables were compared using chi-square test and correlation study (r). The variables were significant(S) at $\mathrm{P}$ - value $<0.05$, highly significant (HS) if $\mathrm{p}<0.01$ and non-significant (NS) if $\mathrm{p}>0.05$. All the statistical analyses were performed using Statistical Package for Social Sciences (SPSS), version 20.

\section{Result}

Table 1: Shows that the mean age of the nurses was $29.60 \pm 5.45$ and $46.7 \%$ of them were in the age group of $30-<40$ years. Regarding gender $90.0 \%$ of the study sample were females, $73.3 \%$ of them had nursing diploma, $43.3 \%$ of them had from $1-<5$ years of experience in hematology units, while $70.0 \%$ of them didn't receive any training courses.

Table 2: Shows that the mean age of patients with thalassemia was $2.28 \pm 1.38$, 58.0\% were females, $38.0 \%$ were preparatory level and $80 \%$ of them received blood transfusion 6 times or more per year.

Table 1. Distribution of nurses' characteristics included in the study $(\mathrm{n}=30)$

\begin{tabular}{|l|c|c|}
\hline Variables & No & \% \\
\hline Age (in years): & & \\
$20-<30$ & 11 & 36.7 \\
$30-<40$ & 14 & 46.7 \\
$40+$ & 5 & 16.7 \\
\hline Mean \pm SD & $\mathbf{2 9 . 6 0 \pm} \mathbf{5 . 4 5}$ \\
\hline Gender: & \multicolumn{2}{|c|}{} \\
Male & 3 & 10 \\
Female & 27 & 90 \\
\hline Educational level & & \\
Nursing diploma & 22 & 73.3 \\
Technical institute & 5 & 16.7 \\
Bachelor degree & 3 & 10.0 \\
\hline Years of experience in hematology unit & \multicolumn{2}{|c|}{} \\
1 - 5 & 13 & 43.3 \\
$5-<10$ & 12 & 40.0 \\
$10+$ & 5 & 16.7 \\
\hline Training about thalassemia and blood transfusion & \multicolumn{2}{|c|}{} \\
Yes & 9 & 30.0 \\
No & 21 & 70.0 \\
\hline
\end{tabular}

Table 2. Distribution of patients' sociodemographic characteristics and frequency of blood transfusion $(n=50)$

\begin{tabular}{|l|c|c|}
\hline Variables & No & $\%$ \\
\hline Age (in years): & \multicolumn{2}{|c|}{} \\
$<12$ & 13 & 40.0 \\
$12-<18$ & 5 & 26.0 \\
$18-<20$ & 12 & 24.0 \\
$20+$ & \multicolumn{2}{|c|}{$\mathbf{2 . 2 8} \pm \mathbf{1 . 3 8}$} \\
\hline Mean \pm SD & \multicolumn{2}{|c|}{} \\
\hline Gender: & 21 & 42.0 \\
Male & 29 & 58.0 \\
Female & \multicolumn{2}{|}{} \\
\hline Educational level: & 16 & 32.0 \\
Illiterate & 19 & 38.0 \\
Preparatory & 10 & 20.0 \\
Secondary & 5 & 10.0 \\
University & \multicolumn{2}{|}{} \\
\hline Frequency of blood transfusion/year: & 10 & 20.0 \\
$<6$ times & 40 & 80.0 \\
$\geq 6$ times & \multicolumn{2}{|c|}{} \\
\hline
\end{tabular}


Table 3: Represents the mean of nurses' knowledge regarding to thalassemia disease and blood transfusion at pre/post program. This table reveals that their mean scores for knowledge about types of thalassemia improved pre/post program (from $4.17 \pm 1.984$ to $7.00 \pm 1.722$, respectively). As well, knowledge about causes of thalassemia improved pre/post program (from $3.33 \pm$ 2.040 to $7.57 \pm 1.501$, respectively). As for knowledge related to methods of diagnosis, it improved pre/post program (from $4.00 \pm 2.084$ to $7.53 \pm 1.592$, respectively). The score of nurses' knowledge about management and instructions given for patients with thalassemia improved at post program compared with preprogram (from $4.10 \pm$ 2.280 to $6.90 \pm 2.040$, respectively). Concerning knowledge related to complications of thalassemia, it improved pre/post program (from $3.87 \pm 2.209$ to $7.20 \pm$ 1.750, respectively). As well, the score of nurses' knowledge about importance and side effects of blood transfusion improved at post program (3.63 \pm 973, $4.27 \pm$ 2.033 vs. $6.866 \pm 1.655,7.03 \pm 1.903$, respectively). The total mean score of nurses' knowledge pre/post program was improved (from $27.431 \pm 1.593$ to $50.37 \pm 7.686$, respectively). There were highly statistically significant differences between pre/post program implementation in all items of nurses' knowledge $(\mathrm{P}<0.00)$.

Table 4: Indicates that there were highly statistically significant differences pre/post program scores in all items of nurses' practice $(\mathrm{P}<0.001)$. There were improvements pre/post program in assessment of body systems, vital signs and administration of IV iron chelation therapy (from $7.566 \pm 2.908,6.448 \pm 3.030, \& 7.60 \pm 3.797$ to $11.800 \pm 4.213,12.034 \pm 3.610, \& 11.700 \pm 3.213$, respectively). As regards nursing role in blood transfusion phases there were improvements in the nurses' practice in preparatory phase, during and after blood transfusion at post program compared with pre program $(7.47 \pm 3.441$, $7.33 \pm 3.565$, \& $7.70 \pm 3.897$ vs. $13.40 \pm 3.654,12.83 \pm$ 2.755 , \& $11.83 \pm 2.890$, respectively). Concerning total scores of nurses' practice for patients, these were a highly statistically significant improvement between pre/post program implementation (36.67 \pm 13.659 vs. $62.07 \pm$ 12.752, respectively).

Table 5: Shows that, there were statistically significant correlations between total nurses' knowledge score, total practice scores in relation to age, years of experience and educational level, ( $\mathrm{r}=0.363,0.667, \& 0.834$, respectively) at $\mathrm{P}<0.05,<0.01 \&<0.01$, respectively). In addition, there were statistically significant correlations between total nursing practice scores and age, years of experience and educational level $(\mathrm{r}=0.470,0$. 655 , \& 0 .386, respectively) at $\mathrm{P}<0.01,<0.01 \&<0.05$, respectively).

Table 6: Shows that, there were statistically significant correlations between total nurses' knowledge score and total practice score pre/post program implementation ( $\mathrm{r}=0.398, \& 0.368$, respectively), at $\mathrm{P}<0.05 \&<0.05$, respectively).

Table 3. Level of nurses' knowledge regarding thalassemia and blood transfusion pre/post program implementation $(\mathrm{n}=30)$

\begin{tabular}{|c|c|c|c|c|}
\hline Items & $\begin{array}{c}\text { Pre program } \\
\text { Mean } \pm \text { SD } \\
\end{array}$ & $\begin{array}{c}\text { Post program } \\
\text { Mean } \pm \text { SD }\end{array}$ & Paired t test & P-value \\
\hline Types of thalassemia & $4.17 \pm 1.984$ & $7.00 \pm 1.722$ & 6.483 & .000 \\
\hline Causes of thalassemia & $3.33 \pm 2.040$ & $7.57 \pm 1.501$ & 12.051 & .000 \\
\hline Methods of diagnosis & $4.00 \pm 2.084$ & $7.53 \pm 1.592$ & 7.737 & .000 \\
\hline Management and instructions given to patients & $4.10 \pm 2.280$ & $6.90 \pm 2.040$ & 4.929 & .000 \\
\hline Complications of thalassemia & $3.87 \pm 2.209$ & $7.20 \pm 1.750$ & 6.873 & .000 \\
\hline Importance of blood transfusion & $3.63 \pm 973$ & $6.866 \pm 1.655$ & 8.385 & .000 \\
\hline Side effects of blood transfusion & $4.27 \pm 2.033$ & $7.03 \pm 1.903$ & 5.667 & .000 \\
\hline Total knowledge & $27.431 \pm 1.593$ & $50.37 \pm 7.686$ & 11.642 & .000 \\
\hline
\end{tabular}

Table 4. Level of nurses' practice pre/post program implementation $(n=30)$

\begin{tabular}{|l|c|c|c|c|}
\hline Items & $\begin{array}{c}\text { Pre program } \\
\text { Mean } \pm \text { SD }\end{array}$ & $\begin{array}{c}\text { Post program } \\
\text { Mean } \pm \text { SD }\end{array}$ & Paired t test & P-value \\
\hline Assessment of the body systems & $7.566 \pm 2.908$ & $11.800 \pm 4.213$ & 6.922 & .000 \\
\hline Measuring of vital signs & $6.448 \pm 3.030$ & $12.034 \pm 3.610$ & 6.856 & .000 \\
\hline Administration of IV iron chelation therapy & $7.60 \pm 3.797$ & $11.700 \pm 3.213$ & 7.532 & .000 \\
\hline Nursing role in preparatory phase of blood transfusion & $7.47 \pm 3.441$ & $13.40 \pm 3.654$ & 9.910 & .000 \\
\hline Nursing role during blood transfusion phase & $7.33 \pm 3.565$ & $12.83 \pm 2.755$ & 7.440 & .000 \\
\hline Nursing role after blood transfusion & $7.70 \pm 3.897$ & $11.83 \pm 2.890$ & 4.979 & .000 \\
\hline Total practice & $36.67 \pm 13.66$ & $62.07 \pm 12.752$ & 11.365 & .000 \\
\hline
\end{tabular}

Table 5. Correlations between total nurses' knowledge score, total practice scores, and age, years of experience and level of education pre program implementation $(n=30)$

\begin{tabular}{|c|c|c|c|c|c|c|}
\hline \multirow{2}{*}{ Item } & \multicolumn{2}{|c|}{ Age } & \multicolumn{2}{|c|}{ Years of experience } & \multicolumn{2}{|c|}{ Level of education } \\
\hline & $\mathbf{r}$ & $\mathbf{P}$ & $\mathbf{r}$ & $\mathbf{P}$ & $\mathbf{r}$ & $\mathbf{P}$ \\
\hline Total knowledge scores & 0.363 & $<0.05^{*}$ & 0.667 & $<0.01^{* *}$ & 0.834 & $<0.01^{* *}$ \\
\hline Total practice scores & 0.470 & $<0.01 * *$ & 0.655 & $<0.01 * *$ & 0.386 & $<0.05^{*}$ \\
\hline
\end{tabular}


Table 6. Correlation between nurses' total knowledge and total practice scores pre/post program implementation

\begin{tabular}{|l|c|c|c|c|}
\hline \multirow{2}{*}{ Item } & \multicolumn{4}{|c|}{ Total Knowledge Score } \\
\cline { 2 - 5 } & \multicolumn{2}{|c|}{ Pre program } & \multicolumn{2}{c|}{ Post program } \\
\cline { 2 - 5 } & $\mathbf{r}$ & $\mathbf{P}$ & $\mathbf{r}$ & \\
\hline $\begin{array}{l}\text { Total Practice Score } \\
\text { Pre program }\end{array}$ & 0.398 & $<0.05^{*}$ & & \\
\hline Post program & & & 0.368 & $<0.05^{*}$ \\
\hline
\end{tabular}

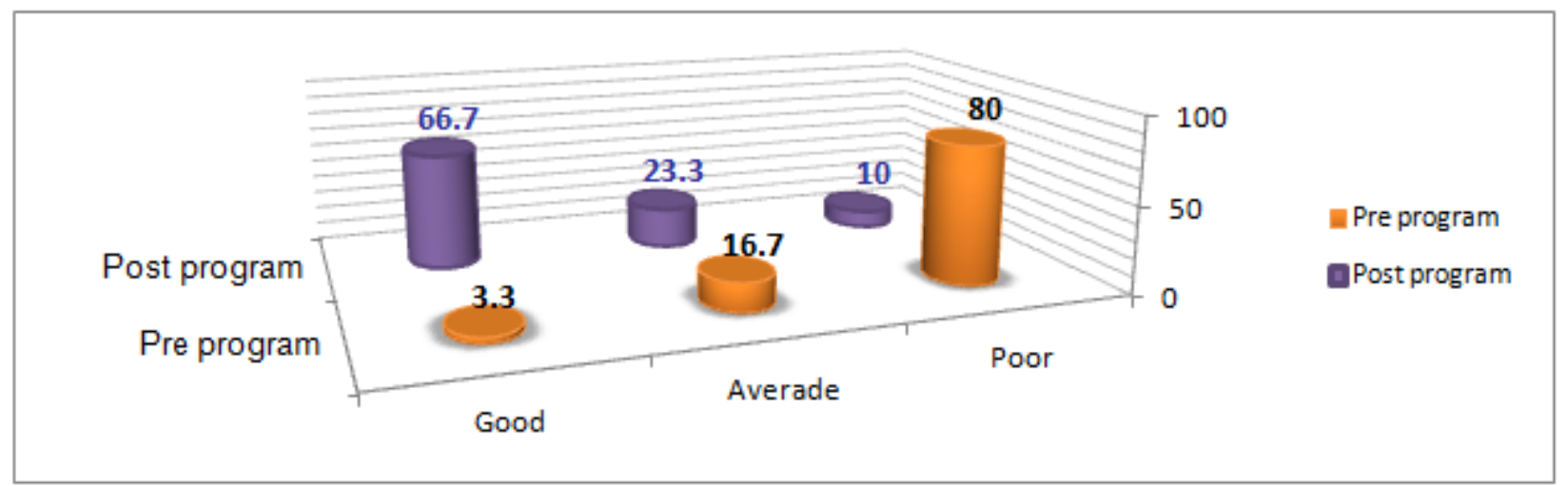

Figure 1. Total level of nurses' knowledge pre/post program implementation

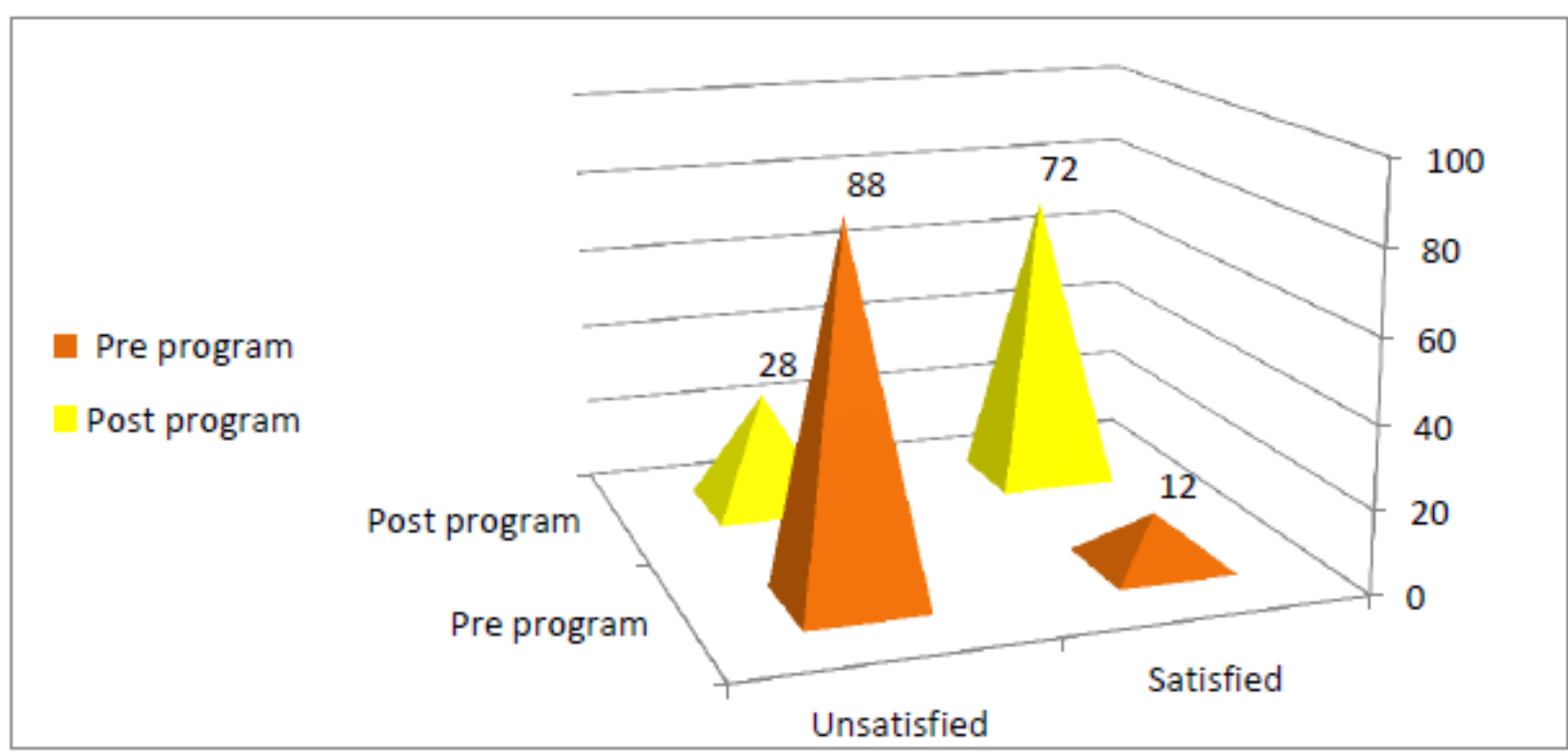

Figure 2. Level of patients' satisfaction regarding to quality of nursing care pre/post program implementation ( $\mathrm{n}=50)$

Figure 1: Illustrates that $80 \%$ of the nurses had poor knowledge level about thalassemia disease and blood transfusion, while $16.7 \%$ had average and $3.3 \%$ had good knowledge level before program implementation, which improved to reach $66.7 \%$ had good knowledge level, $23.3 \%$ had average level and $10.0 \%$ had poor knowledge level after program implementation.

Figure 2: Illustrates that, $88.0 \%$ of patients were unsatisfied for quality of nursing care pre program, which improved to $72.0 \%$ satisfied regarding quality of nursing care post program.

\section{Discussion}

Thalassemia is a complex group of diseases common in Mediterranean regions and Southeast Asia. Worldwide, there are 350,000 births per year with serious hemoglobinopathies. Blood transfusion is the mainstay of care for individuals with thalassemia major [7]. The nurse plays a vital role in the care of patients with thalassemia. It is therefore of the utmost importance to have a nursing service that is integrated, seamless and suitable for patients in both the acute and community setting. Nurses are also essential in helping thalassemic patients to become aware in their own condition, teaching effective techniques for self management, the prevention of complications and the transition of pediatric patients to the adult team of healthcare specialists, as well as in genetic counseling [19]. The aim of this study was to evaluate the effect of an educational program on improving quality of nursing care of patients with thalassemia major as regards blood transfusion.

Discussion of the study findings are categorized under the following parts: 


\section{First part: Nurses' and patients' characteristics of the studied sample}

Thirty nurses caring of thalassemia patients receiving blood transfusion were included in the present study, nearly half of them their age ranged between $30-<40$ years, this result may be due to that this age group is the common age of nurses who give care for the thalassemic patients under blood transfusion. The present study result revealed that more than two fifth of them had experience less than 5 years and more than two third of them did not attend any training program about thalassemia and blood transfusion.

Regarding the educational level in the current study, the highest percentage of nurses representing less than three quarter were diploma holders which might elaborate the current condition of nursing qualification, followed by technical institute graduates. This is due to the high demand of the Egyptian hospitals on the technical secondary schools of nursing recruitment. This finding was similar to that of Maarouf [20], who found that, more than half of study nurses were nursing diploma, followed by one fifth were bachelor degree holders, and slightly less than quarter of nurses were having nursing diploma in addition to diploma specialty.

Concerning years of experience of nurses in the present study, more than two fifth of them had experience ranged from one to less than 5 years and two fifths from 5 to less than 10 year. These findings were in agreement with that of a study conducted by Elkattan [21], who found that more than two thirds of the total sample under study had experience less than 10 years. This might be due to that the most common age group of the studied nurses is in the youngest age group ranging between $18-<30$ years. In addition, Shafik and Abd Allah [22], mentioned that most of the study sample were having experience from $5-<10$ years, in hematology units.

Considering training program related to thalassemia and blood transfusion, the results of the present study showed that, more than two thirds of studied nurses did not attend training program related to thalassemia and blood transfusion, which may be attributed to the shortage in nursing staff, so these units can't let them attend any training courses to prevent interruption of work due to their absenteeism or this may be due to that the unit do not carry out training programs for nurses. This finding was supported by the result of a study conducted by Salem [23], who stated that more than three quarters of nurses did not receive any training courses and in agreement with Woorlery et al. [24], who reported that the majority of nurses in their study didn't receive any training courses.

As regards patients' characteristics, the present study showed that two fifth of the study sample were having less than 12 years, this may be due to a decrease in life expectancy of patients with thalassemia major. This result agree with DeBaun et al. [3], who said that severe thalassemia can cause early death (between ages 20 and 30 years) due to heart failure.

In accordance to gender, the finding of the present study revealed that, both females and males are affected with more female predominance than males, this may be attributed to the fact that thalassemia are genetic blood disorders that affect both females and males. This study result agree with Smith [25], who in a very recent study, stated that both alpha and beta-thalassemia are usually inherited in an autosomal recessive pattern. This means that males and females are affected as it does not involve the sex chromosome and both parents must be carriers of a gene mutation.

The present study refers to that the majority of the study sample receive blood transfusion equal and more than six times per year, this refers to that blood transfusion is the first and mainstay of care for individuals with thalassemia major and chronic transfusions prevent most of the serious growth, skeletal and neurological complications of thalassemia major. This study result is in agreement with Northern California Comprehensive Thalassemia Center [26], which stated that the aim of transfusion therapy is to permit normal growth, activity level, and to prevent skeletal changes associated with bone marrow hyperplasia. Adequate transfusion therapy will also reduce splenomegaly, hypersplenism and decrease absorption of dietary iron.

Second part: Assessment and evaluation of the nurses' level of knowledge and practice:

Nurses have an important role in a safe blood transfusion. Therefore, it is crucial for nurses to have sufficient knowledge of situations, amount and methods of using blood components, possible side effects and necessary care.

Regarding nurses' knowledge of thalassemia and blood transfusion, the present study showed a significant improvement in all items of knowledge and practice among the studied nurses after the educational program implementation and this led to improvement of patients' outcomes. This improvement may be due to many reasons as, knowledge refreshment through the program sessions, relevance of the items of the program content, clarity of program materials and easy language of the educational program. This result is congruent with Aslani et al. [8], who showed that nurses' knowledge and practice of using needles with appropriate diameter was good but they did not have correct and scientific knowledge of indications and method of heating blood. In addition, Khouri [27] reported that the education may enhance the capacity of nurses to be effective caring practitioners. Additionally, Hijji et al. [15] high lighted that preventing and recognizing a transfusion reaction requires nurses to have adequate knowledge.

The unsatisfactory knowledge of the studied nurses in the present study before implementation of the educational program may be due to lack of preparation during the basic education or lack of desire of nurses to acquire new knowledge, overload in the working situation and lack of continuous educational courses related to care of patient with thalassemia under blood transfusion. Nurses play a significant role in correct, scientific and safe usage of blood and its components and if they can do them correctly, the probability of incidence of blood transfusion risks will be reduced to minimum as identified by Aslani et al. [8].

The present study revealed that there were statistically significant differences between pre/post educational program regarding to nurses' practice namely physical assessment, measuring vital signs, administration of iron chelation therapy and blood transfusion. These results may be due to the positive effect of the educational program, which improved nurses' practice. In the same line, the incompetence in nurses' level of practice pre implementation 
of the educational program may be due to lack of supervision, neglection from nurses, shortage of qualified staff, as well as shortage of an orientation program for the nurses. This study findings were supported by those of Alomar [28] and Deborah and Corcoran [29], who stated that as regards total nurses' practice near two thirds of the study nurses had unsatisfactory practice regarding nursing management of patients and this agreed with Shafik and Abd Allah [22], who reported that the majority of nurses didn't perform blood transfusion accurately. Untrained nurses allowed to administer blood transfusions is serious enough; it could have contributed to fatalities among patients, because lack of training contributed to committing errors.

\section{Third part: Patients' satisfaction regarding to quality of} nursing care pre/post educational program.

Patients' satisfaction is generally accepted as a crucial indicator of the quality and effectiveness of nursing care. This study result showed that the majority of patients were not satisfied for quality of nursing care pre program, which improved post program. This result may be due to the effectiveness of the educational program that reflected on the improvement of nurses' knowledge and practices which in turn can effect on patients' outcomes and satisfaction. This result agreed with Ndambuki [12], who reported that, the quality of care provided to patients can be improved through education and a better understanding and appreciation of nursing art.

Fourth part: Correlations between nurses total knowledge and total practice score and age, years of experience and level of education.

This study finding revealed that there was a statistically significant correlation between total score of nurses' knowledge and practice pre program implementation and age. As well, the result of this study showed that there was a significant correlation between the educational level and total score of nurses' knowledge and practice. This may be due to that less than three quarter of the studied nurses had diploma in nursing, which might elaborate the current condition of nursing qualification. These results were supported by Deborah and Corcoran [29], who reported that, there is a positive relation between nurses' knowledge, nursing practice and level of education which affect quality of nursing care that the patients receive so, the standard of quality of nursing care was affected by the nurses' level of education. However, the result of this study contradicted with Deborah and Corcoran [29], who reported that there was no statistically significant relation between nurses' performance and academic qualification.

The current study result showed that there are statistically significant positive correlations between years of experience, and the nurses' knowledge and practice pre program, as the level of knowledge and practice increased with greater years of experience. This result is supported by Shafik and AbdAllah [22], who stated that, the greater the years of experience of the nurses, the greater their knowledge and practices.

The present study finding revealed that, there was a statistically significant correlation between total score of nurses' knowledge and practice, which indicates the positive relation between knowledge and practice. This result refers to the level of practice influenced by the level of knowledge. However, without proper knowledge, nurses may initiate a transfusion at a rate either slower or faster than recommended. The outcome of this could be either prolongation of the transfusion duration with an increased risk of bacterial contamination or the occurrence of severe transfusion reaction. This study finding is in accordance with Hunter [30], who identified that most importantly, nurses can learn as many skills, but all of that would be a waste if they don't implement the skills in their clinical practice.

\section{Limitation of the Study}

There was a difficulty in conducting the program sessions during the working hours, as well the unavailability of a suitable place to carry out the program.

\section{Conclusion}

The educational program had a positive effect on nurses' knowledge and practice related to thalassemia and blood transfusion, which improved the quality of nursing care, as well as increased patient satisfaction.

\section{Recommendations}

Based upon the results of the current study, the following recommendations are suggested

- A specialized orientation program should be developed for newly appointed nurses to prepare them before working at the hematology departments.

- Further studies should be conducted to improve nurses' knowledge and practice regarding to blood transfusion and care of patients with thalassemia.

- Developing and executing an in-service training program for nurses emphasizing the weak points to increase their knowledge and practice and continuously supervise this task

\section{References}

[1] Ali, S., Sabih, F., Jehan, S., Anwar, M., \&Javed, S. (2012) Psychological distress and coping strategies among parents of beta-thalassemia major patients. International Proceedings of Chemical, Biological and Environmental Engineering; 27: 124-128.

[2] Ismail, M., Chun, C.Y., Yusoff, N.A.M., Shahar, S.S., \& Abdul Manaf, Z. (2013). Quality of life among thalassaemia children, adolescent and their caregivers. SainsMalaysiana; 42(3): 373-380.

[3] DeBaun, M.R., Glauser, T.A., Siegel, M., Borders, J., \& Lee, B. (2011). Noninvasive central nervous system imaging in sickle cell anemia: A preliminary study comparing transcranial, Doppler to magnetic resonance angiography. American Journal of Pediatric Hematology/Oncology; 17, 29-33.

[4] Pillitteri, A. (2014). Maternal \& child health nursing, care of the child bearing \& childrearing family (7th ed.). Lippincott: Williams, \&Wilkins, p.1289.

[5] Abu Shosha, G.M. (2014). Needs and concerns of Jordanian mothers with Thalassemic children: A qualitative study. J Am Sci; 10(1): 11-16.

[6] Taylor, C. (Ed.), Cohen, H., Mold, D., Jones, H.et al., (2010). On behalf of the serious hazards of transfusion (SHOT) steering group. The 2009 Annual SHOT Report.

[7] Soc Guidelines. (2012). Standards of care guidelines for thalassemia, Children's Hospital \& Research Center Oakland Hematology/Oncology Department. Available at: www.childrenshospitaloakland.org. 
[8] Aslani, Y., Etemadyfar, S., \&Noryan K. (2010). Nurses' knowledge of blood transfusion in medical training centers of Shahrekord University of Medical Science in 2004, IJNMR; 15(3): pp.141-144.

[9] Burhans, L., \&Alligood, M. (2010): Quality nursing care in the words of nurses.

[10] Leana, R.U., \& Joanne, R. N. (2004): A Survey of the quality of nursing care in several health districts in South Africa. Available at:

http://bmcnurs.biomedcentral.com/articles/10.1186/1472-6955-3-1.

[11] American Nursing Association. (2014). Connection between nurse staffing and patient outcomes can be made in all hospital clinical areas with expanded measures. Available at: www.nursingworld.org.

[12] Ndambuki, J. (2013). The level of patients' satisfaction and perception on quality of nursing services in the Renal Unit, Kenyatta National Hospital Nairobi, Kenya. From patient satisfaction. Open Journal of Nursing; 3: 186-194.

[13] De Freitas, J., De Camargo Silva, A., Minamisava, R., Bezerra, A., And De Sousa,M. (2014). Quality of nursing care and satisfaction of patients attended at a teaching hospital. Rev. Latino-Am. Enfermagem; 22:.3.

[14] Taher, A., Vichinsky, E., Musallam, K., Cappellini, M., \& Viprakasit, V. (2012). Guidelines for the management of non transfusion dependent Thalassemia (NTDT). Thalassaemia International Federation. Available at: www.thalassaemia.org.cy.

[15] Hijji, M.B., Oweis, A.E., \&Dabbour, R.S. (2012). Measuring knowledge of blood transfusion: A survey of Jordanian Nurses. American International Journal of Contemporary Research, October; 2: 10.

[16] Department of Air Force. (2014). Surgical service specialty nursing care of the surgical patient, Headquarters US Air Force QTP 4N1X1, Volume 06. Washington. DC 20330-5000 http://static.epublishing.af.mil/production/1/af_sg/pub lication/qtp4n1x1x-06/qtp4n1x1x-06.pdf.

[17] Taylor, C. Lillis, C., LeMone, P., Lynn, P. (2008). Fundamental of nursing, the art and science of nursing care, ( $6^{\text {th }}$ ed.). Lippincott William and Wilkins, Philadelphia, pp.570-582.

[18] Risser, N. (1975). Development of an instrument to measure patient satisfaction with nurses and nursing care in primary care settings. Nursing Research; 24:45-52.
[19] Elsayed, L.A., \& Abd El-Gawad, S.M. (2015). Nursing guidelines for children suffering from beta thalassemia. International Journal of Nursing Science; 5(4): 131-135.

[20] Maarouf, D. (2012). Nurse's performance for patients with traumatic head injury during golden hours. Master Science in Nursing Degree, Medical Surgical Nursing. Faculty of Nursing, Ain Shams University, pp. 97-98.

[21] Elkattan, B. (2013. Impact of training program regarding for neurological patients in coma upon nurses' performance. Doctoral Thesisin Nursing Science, faculty of Nursing, AinShams University, p.120.

[22] Shafik, S., \& Abd Allah, E. (2015). Improving the quality of nursing care for patients with leukemia in day care units through nursing education. American Journal of Nursing Science; 4(3): 63-72.

[23] Salem, B. (2010). Evidence-based guideline for care of neonates with respiratory distress. Doctorate in Nursing Science Thesis, Medical-Surgical Nursing, Faculty of Nursing, Ain Shams University, Cairo, pp.143-144.

[24] Woorlery, V.A., Buchsel, P., \&Parchem, C., (2012). Ambulatory care of the bone marrow transplant client. A multicentre casecontrol study. J Epidermal Community Health, Jun; 54(6): 421-426.

[25] Smith, Y. (2015). Thalassemia genetic prevalence. Available at: http://www.news-medical.net/health/Thalassemia-GeneticPrevalence.aspx.

[26] Northern California Comprehensive Thalassemia Center. (2012). UCSF Benioff Children's Hospital Oakland Available at: thalassemia.com/treatment-transfusion.aspx.

[27] Khouri, R.I. (2011). Impact of an education program on nursing students caring \& self-perception in intensive clinical training in Jordan. Depress Browse Journal. Advances in Medical Education and Practice. 2:.173-185.

[28] Alomar, H. (2012). Assessment of nurse’s performance for caring of patients in mechanical ventilator. Master Science in Nursing Degree, Faculty of Nursing, Ain Shams University, pp.102-153.

[29] Deborah, J.A., \& Corcoran, F. (2011). Acute undifferentiated leukemia in adults, (7th ed.) Hong Kong: Excel Typesetter, pp.380-400.

[30] Hunter, K. (2010). Nursing skills. The importance of practical experience. Available at: http://ezinearticles.com/? Nursing-SkillsThe-Importance-of-Practical-Experience \& id=3797. 